\title{
A RESISTÊNCIA DE PERPERA SURUÍ FRENTE AO GENOCÍDIO INDÍGENA CONTEMPORÂNEO BRASILEIRO, NO FILME EX-PAJÉ: BIOPOLÍTICA, SUBJETIVAÇÃO E PODER PASTORAL
}

\section{PERPERA SURUI'S RESISTANCE TO THE CONTEMPORARY BRAZILIAN INDIGENOUS GENOCIDE IN THE EX-PAJÉ FILM: BIOPOLITICS, SUBJECTIVATION AND PASTORAL POWER}

\section{RAMIRO, John José}

Mestrando na Universidade Estadual de Maringá

Universidade Estadual de Maringá

E-mail: johnjramiro@gmail.com

ORCID ID: 0000-0002-0772-8972

\section{FURTADO, Bruna Plath}

Doutora em Letras com Área de Concentração em Estudos Linguísticos pelo Programa de Pósgraduação em Letras da Universidade Estadual de Maringá

Universidade Estadual de Maringá

E-mail: brunaplath@gmail.com

ORCID ID: 0000-0001-8237-1451

\section{RESUMO}

Este trabalho tem como objetivo principal apresentar um estudo acerca da resistência indígena marcada na materialidade fílmica de Ex-Pajé (2018). Para tanto, tomamos como abordagem teóricometodológica a análise de discurso, sobretudo a perspectiva denominada como arque-genealógica que recuperamos da obra do filósofo francês Michel Foucault. Nesse sentido, os principais conceitos mobilizados ao longo do desenvolvimento do artigo foram: dispositivo (AGAMBEN, 2009), objetivação e subjetivação (FOUCAULT, 1995) e poder pastoral (FOUCAULT, 2008a). O documentário Ex-Pajé emerge em 2018 sobre a direção de Luiz Bolognesi e possui uma narrativa que incide principalmente sobre a atuação de Pepera Suruí, o Ex-pajé que dá nome ao filme, junto aos integrantes do povo Paiter Suruí e junto à prática de culto cristão estabelecido entre seu povo desde a invasão branca a que foram submetidos no final da década de 1960. A partir da materialidade 
discursiva do filme em questão e compreendendo sua constituição enunciativa, tomamos como escopo dez frames que nos possibilitam demonstrar como o exercício de um poder que identificamos como pastoral atua na condução dos indígenas aí objetivados e subjetivados como rebanho e que se deixam conduzir de uma prática ancestral ao culto cristão. Ao mesmo tempo em que subjetiva os indígenas como rebanho, o poder pastoral simultaneamente ao poder disciplinar, ao poder regulamentar e ao poder soberano contribuem para o genocídio da cultura Paiter Suruí, ao passo que Pepera Suruí, objetivado pelo poder pastoral como ex-pajé, exerce suas práticas de resistência, marcando seu espaço de atuação mesmo no interior da igreja levantada dentro da Floresta, mantendo-se Pajé.

Palavras-chave: Objetivação. Subjetivação. Poder Pastoral. Resistência Indígena

\section{ABSTRACT}

This work has as main objective to present a study about the indigenous resistance marked in the filmic materiality of Ex-Pajé (2018). For this purpose, we take discourse analysis as a theoreticalmethodological approach, especially the perspective called archegenealogical that we retrieved from the work of the French philosopher Michel Foucault. In this sense, the main concepts mobilized throughout the development of the article were: device (AGAMBEN, 2009), objectification and subjectivation (FOUCAULT, 1995) and pastoral power (FOUCAULT, 2008a). The documentary Ex-Pajé emerges in 2018 under the direction of Luiz Bolognesi and has a narrative that focuses mainly on the performance of Pepera Suruí, the Ex-Paje that gives the film its name, together with members of the Paiter Suruí people and with the practice of Christian cult established among its people from the white invasion to which they were subjected in the late 1960s. From the discursive materiality of the film in question and understanding its enunciative constitution, we took as scope ten frames that allow us to demonstrate how the exercise of a power that we identify as pastoral acts in the conduct of indigenous peoples objectified and subjectified there as a flock and who allow themselves to be led from an ancestral practice to Christian worship. At the same time that it subjects the indigenous peoples as a flock, pastoral power simultaneously to disciplinary power, regulatory power and sovereing power contributes to the genocide of the Paiter Suruí culture, while Pepera Suruí, objectified by the pastoral power 
as a former shaman, except his practices of resistance, marking his space of action even within the church raised within the Forest, remaining Pajé.

Keywords: Objectivation. Subjectivation. Pastoral power. Indigenous resistence.

\section{INTRODUÇÃO}

"Na imagem, figuravam Benjamin e Rosie à entrada de uma igreja. Arcanjo comentou:

[...]

- Vocês não saíram da África quando vos levaram nos barcos como escravos. Vocês saíram quando entraram na igreja e ajoelharam perante Jesus."

(Mia Couto)

O sujeito indígena, centralizado no jogo de forças em que o poder que subjetiva é exercido, tem resistido às práticas do genocídio contemporâneo. Nessa luta, o garimpo ilegal, a invasão de terras, a marginalização, as epidemias que atravessam os mais de 500 anos desde o "descobrimento", o contato com o homem branco e o enfraquecimento das instituições federais se mostram como práticas biopolíticas atuando na objetivação/subjetivação do sujeito indígena.

Partindo dessas condições de emergência, o objetivo principal deste artigo é tecer uma análise sobre a resistência marcada na imagem e na materialidade fílmica e documental de Ex-Pajé (2018), a partir do subsídio teórico-metodológico da análise de discurso. Para tanto, mobilizamos os conceitos de dispositivo, desenvolvido por Giorgio Agamben (2009), para pensar aqui o dispositivo colonizatório, o qual se renova na contemporaneidade promovendo uma forma de doutrinação religiosa com o estabelecimento das igrejas neopentecostais inseridas nas aldeias, de objetivação/subjetivação, a partir de Foucault (1995), para compreender como na materialidade do filme o homem indígena, sobretudo na figura do pajé Perpera Suruí, é transformado em sujeito, e de poder pastoral, de acordo com Foucault (2008a). Nesse sentido, o trabalho procura demonstrar como em Ex-Pajé (2008) observamos uma resistência que se marca frente à inserção de uma igreja evangélica que pratica um processo biopolítico de genocídio dos sujeitos indígenas, subjetivando-os em outros sujeitos. Para o desenvolvimento específico 
da análise proposta neste trabalho, focalizamos dois momentos do filme Ex-Pajé (2018), sendo eles: I. a apresentação do primeiro contato documentado em imagens dos Paiter Suruí com os brancos e II. a atuação de Perpera (o denominado ex-pajé e que também dá nome ao documentário) na instituição religiosa cristã inserida em sua aldeia.

A materialidade sobre a qual nossas análises incidem, portanto, é o filme documental Ex-Pajé (2018), dirigido por Luiz Bolognesi, e que narra a trajetória de Perpera do povo Paiter Suruí, cuja função de pajé quer se crer destituída com a entrada de uma missão evangélica na aldeia que, conforme se relata no documentário, objetiva como demoníacos os rituais ancestrais espirituais nativos. Além disso, o filme focaliza questões culturais e saberes originários que são modificados a partir do contato com o homem branco.

\title{
IMAGEM E(M) DISCURSO, MATERIALIDADE FÍLMICA DOCUMENTAL, DISPOSITIVO E BIOPOLÍTICA
}

\author{
"Benjamin não entendeu a insinuação, entretido a \\ investigar os detalhes. Vícios de historiador, ele não via \\ fotos, ele lia imagens." \\ (Mia Couto)
}

A imagem é uma das formas mais antigas de linguagem e pode ser compreendida enquanto uma capacidade humana de expressão e, nesse sentido, de enunciação discursiva. A partir de imagens, historicamente, interagimos, criamos e reproduzimos narrativas e podemos também acessar um "espaço arqueológico" de discursos. Uma imagem, enquanto enunciado discursivo, é composta por símbolos ou objetos e sempre se remeterá a outra(s) imagem(s) e materialidades enunciativas, visto que o enunciado se constitui em "um conjunto de domínios em que tais objetos podem aparecer e em que tais relações podem ser assinaladas" (FOUCAULT, 2008b, p. 102). Na intersecção, portanto, da compreensão da imagem como enunciado e como lugar de emergência simbólica, podemos recuperar as palavras de Manguel quando afirma que:

As imagens que formam nosso mundo são símbolos, sinais, mensagens e alegorias. Ou talvez sejam apenas presenças vazias que completamos com o nosso desejo, experiência, questionamento e remorso. Qualquer que seja o caso, as imagens, assim como as palavras, são a matéria de que somos feitos (MANGUEL, 2001, p. 21). 
Donde compreendemos que, assim como enunciados discursivos cuja materialidade seja a linguagem verbal, os enunciados de materialidade imagética ou verbo-imagética, do mesmo modo, constituem processos de objetivação e subjetivação visto que tomam os seres humanos como objeto. A respeito dessa compreensão de imagem como enunciado, corrobora Burke (2007) ao abordar o uso de imagens como evidência do passado, sobre o que, ao pensarmos no filme $E x$ Pajé (2018), nos propomos ao exercício da possibilidade de recuperar o passado problematizando a violência atual contra as populações indígenas, especificamente, dos povos Paiter Suruí. Sobre as imagens, Burke nos faz pensar na possibilidade de "imaginar' o passado de forma mais vívida", pensaremos também no presente "[...] nossa posição facea-face com uma imagem nos coloca 'face a face com a história". E para isso, nosso estudo incide sobre a imagem em movimento, especificamente o cinema.

\section{MATERIALIDADE FÍLMICA DOCUMENTAL}

O cinema, ainda que não seja imagem fixa, é composto por frames, ou seja, um vasto número de imagens que geram o efeito de movimento. Dessa forma, os discursos, os jogos de poder e o regime de verdade se articulam na produção de sentido(s), promovendo um complexo exercício discursivo de leitura para o leitor de imagens.

Para Silva, a partir da leitura de Foucault (2007): "O cinema é, pois, um espaço institucional que, por meio da escritura fílmica, organiza signos em torno de contingências históricas, culturais e econômicas [...]" (SILVA, 2014, p. 159). Ao trazermos como objeto de estudo um filme documentário sobre os povos indígenas, a partir das imagens, constituídas através dos símbolos, nos ancoramos na compreensão dos símbolos como produtores de sentidos.

Por se tratar de um filme documentário, pensamos no corpus aqui analisado como uma manifestação do real, enquanto uma manifestação de verdade, mas até que ponto a materialidade fílmica documental é efetivamente verídica? Há interferência por meio do diretor e sua equipe de fotografia ou da equipe de edição? São estas perguntas que buscamos problematizar a seguir na medida em que buscamos, também, entender quais as condições de emergência do filme Ex-Pajé (2018).

A respeito de tais questões, há uma concordância geral entre os estudiosos de cinema documentário de que não é possível se chegar a uma realidade no interior deste gênero sem que não haja também 
minimamente um tom ficcional, tendo em vista que, no documentário, ainda que carregue na sua etimologia a palavra documento, o que faz pressupor certa objetividade, haverá sempre uma interferência a partir da interpretação do diretor e de sua equipe, que podem manipular e ou direcionar o olhar do leitor para uma forma de realidade, visto que a manifestação da verdade no documentário se insere num regime de verdade que, como define Foucault (2014a), torna imperativo aos indivíduos inseridos nele a realização de determinados atos de verdade, o cumprimento de determinadas obrigações que possibilitam a tais indivíduos a manifestação do verdadeiro.

Nesse sentido, extrapolando a ideia de que a autoria residiria no indivíduo, por trás da emergência de Ex-Pajé (2018), compreendido em sua dimensão discursiva, reconhecemos uma autoria, nos moldes da formulada por Foucault (1996, p. 26), entendida como procedimento de controle discursivo, como "princípio de rarefação de um discurso". Desse modo, o autor é uma função que se exerce pelo estabelecimento de uma unidade de coerência que atua na seleção e construção dos enunciados que, enquanto filme, incluem recortes de cena, enquadramento de câmera, uso de recursos sonoros, iluminação e construção narrativa; a função de autoria se exerce como um operador da verdade ${ }^{1}$. Nessa dimensão, mesmo o cinema de documentário é resultado de uma vontade de verdade no interior da qual o filme documental atua como lugar de manifestação da verdade compreendida, nos termos de Foucault (2007, p. 14), não como o verdadeiro que uma vez descoberto deve, impreterivelmente, ser aceito, mas como um conjunto de regras a partir das quais é possível diferenciar o verdadeiro e o falso, sendo a verdade definida, então, como "um conjunto de procedimentos regulados para a produção, a lei, a repartição, a circulação e o funcionamento dos enunciados". Enquanto testemunha de verdade, portanto, o cinema documental funciona como um cinema de "prova" de um momento específico da história, na medida em que dá espaço de emergência para os discursos acerca dos objetos tomados em seu interior. Nas palavras de Oliveira e Tasso (2015), a partir da leitura de Teixeira (2012), o filme documentário:

[...] ainda carrega para muitos estudiosos, a característica de "prova", ou seja, nasceu com a função de provar um fato, de ser um documento em movimento, ou para o próprio

1. Foucault (2014), ao definir aspectos relativos a uma manifestação ritual da verdade denominada como aleturgia, descreve os papeis que podem ser desempenhados pelo sujeito na manifestação da verdade, sendo eles: operador da verdade, espectador da verdade e objeto da verdade. 
Teixeira (2012, p. 253) 'um conjunto de documentos que a consistência de 'prova' a respeito de uma época'. Ele estaria a serviço da materialização da realidade, da "revelação da verdade (OLIVEIRA E TASSO, 2015, p. 124).

Durante os 81 minutos de Ex-pajé (2018), segundo filme dirigido por Luiz Bolognesi, o leitor se vê diante de uma experiência imagética que proporciona reflexões sobre o colonialismo e o decolonialismo, de modo que a temática indígena ocupa o grande cerne de desenvolvimento da narrativa.

O filme Ex-Pajé (2018) não possui uma narração em "off", o que o difere de muitos outros documentários e possibilita que apenas os indígenas "contem", por meio das imagens e de sua língua materna, a narrativa. Para isso, de acordo com Otto e Souza (2020):

O diretor afasta-se do modelo documental clássico pontuado na narração explicativa e no método de entrevistas para dar lugar a uma câmara meramente observadora. As cenas dividem-se em flagrantes de situações que acontecem em tempo real e em encenações dos próprios moradores da aldeia para situações que já aconteceram e permanecem marcantes em suas memórias (OTTO e SOUZA, 2020, p. 2).

Dessa forma, para a análise das imagens, recorremos, como destacado inicialmente, a conceitos advindos dos estudos teóricometodológicos da Análise do Discurso Foucaultiana. Para tanto, destacamos, na subseção seguinte, os conceitos de dispositivo e biopolítica.

\section{DISPOSITIVO E BIOPOLÍTICA}

Para Agamben, o dispositivo "É um conjunto heterogêneo, linguístico e não-linguístico", uma "rede" que possui "[...] sempre uma função estratégica, concreta e se inscreve sempre numa relação de poder", de modo que resulta de uma relação de poder e de relações de saber" (AGANBEM, 2009, p. 40 ). A respeito disso, o autor explica que:

De fato, todo dispositivo implica um processo de subjetivação, sem o qual o dispositivo não pode funcionar como dispositivo de governo, mas se reduz a um mero exercício de violência. Foucault assim mostrou como, numa sociedade disciplinar, os dispositivos visam, através 
de uma série de práticas e de discursos, de saberes e de exercícios, à criação de corpos dóceis, mas livres, que assumem a sua identidade e a sua 'liberdade' de sujeitos no próprio processo do seu assujeitamento. Isto é, o dispositivo é, antes de tudo, uma máquina que produz subjetivações e somente enquanto tal é também uma máquina do governo. (AGAMBEN, 2009, p. 46).

Em relação especificamente à questão do poder, Foucault (2007) apresenta uma proposta diferente da concepção marxista em que o poder está exclusivamente ligado ao Estado. O poder, para Foucault, não é unicamente repressivo, mas está inserido em uma rede social e é exercido em práticas constantes do cotidiano. O poder circula entre enunciados, e Foucault demonstra a sua preocupação em entender o poder nos seus "detalhes, com sua especificidade, suas técnicas e suas táticas" (FOUCAULT, 2007, p. 10).

Desse modo, as reflexões que recuperamos do filósofo nos permitem concluir que o poder não está em nenhum ponto da estrutura social, ele funciona em uma rede de dispositivos ou mecanismos aos quais ninguém escapa, dos quais não existe exterior possível, limites ou fronteiras, por isso, a ideia geral é a de que o poder não é um objeto, uma "coisa" que pertence a alguém como é comumente abordado por outras correntes teóricas, porque o poder não existe de fato, o que existem são práticas ou relações de poder. Nessa perspectiva filosófica, compreendese que o poder se dissemina por toda estrutura social. Nas palavras de Machado (2007):

Não se explica inteiramente o poder quando se procura caracterizá-lo por sua função repressiva. O que lhe interessa basicamente não é expulsar os homens da vida social, impedir o exercício de suas atividades, e sim gerir a vida dos homens, controla-las em suas ações para que seja possível e viável utilizá-las ao máximo, aproveitando suas potencialidades e utilizando um sistema de aperfeiçoamento gradual e continuo de suas capacidades (MACHADO, 2007, p. 20).

Nesse ínterim, ao estudar os efeitos do poder na sociedade, Foucault observa como o poder, assim como ao dispositivo, estão ligados modos de objetivação/subjetivação quanto desenvolve outros conceitos por 
meio dos quais podemos observar o controle social, são eles: o biopoder e a biopolítica.

Ao tratar de tais conceitos, o autor descreve como, a partir do final do século XVIII, é possível identificar em nossa sociedade um fenômeno por meio do qual há uma tomada de poder sobre os seres humanos enquanto seres vivos. Essa forma de poder, que o filósofo denominou como biopoder, diferencia-se do que Foucault (1999) identifica como poder de soberania, no interior do qual o soberano exerce seu direito de vida e de morte sobre os súditos. Na soberania, prevalece a vontade do soberano sobre a vida e a morte dos súditos, de modo que ele pode matar, exercendo seu direito sobre a vida. Assim, o poder ligado à figura do soberano "É o direito de fazer morrer ou de deixar viver" (FOUCAULT, 1999, p. 287) e no qual a dissimetria evidencia a morte.

No que concerne ao biopoder, paralelamente ao poder do soberano, Foucault (1999) destaca, a partir do século XIX, uma transformação no direito político que não substitui a soberania, mas estabelece um novo direito que emerge complementarmente e que penetra, perpassa e modifica o poder soberano. Nesse novo direito, estabelece-se um poder inverso que instaura a máxima de fazer viver e deixar morrer.

Esta "nova" forma de poder, o biopoder do direito de fazer viver e deixar morrer, está ligada a tecnologias de poder que tratam do corpo e da população. No primeiro caso, temos as técnicas do poder disciplinar que se concentram no corpo individual. No segundo caso, o poder incide sobre a população estabelecendo uma tecnologia de poder, a biopolítica, que constitui mecanismos reguladores da população com fins de fazer viver. Desse modo, Foucault (1999) descreve um jogo de mudança na lógica do poder que fará sobressair ao poder do soberano, desde os anos finais do século XVIII, a biopolítica por meio da regulamentação da população e disciplinarização do corpo. Ambos os mecanismos, disciplinar e regulamentador, não se excluem, mas, na maioria dos casos como evidencia o filósofo, se articulam.

Sobre essas tecnologias conceituadas por Foucault, Peixoto e Martins (2009) nos explicam que:

O conceito deixa de se referir a um regime de poder específico e situado historicamente para se constituir como grade de análise das relações de poder, entendidas aqui como 'condução de condutas' ou 'arte de governar'. Enfim, a noção de governamentalidade passa a englobar todo o campo estratégico das relações de poder, ou seja, a 
multiplicidade indefinida de técnicas e táticas destinadas a modificar e conduzir a conduta dos outros (PEIXOTO E MARTINS, 2009, p. 9).

Enquanto um "poder que se incumbiu tanto do corpo quanto da vida, ou que se incumbiu [...] da vida em geral, com o pólo do corpo e o pólo da população" (FOUCAULT, 1999, p. 302), Foucault nos descreve paradoxos do biopoder que residem em observar circunstâncias nas quais, no interior das tecnologias disciplinar e regulamentar, será exercido o direito de matar, aproximando o biopoder do poder soberano. Tal paradoxo observável no biopoder pode ser explicado, conforme Foucault (1999, p. 304), pois há, "nesse domínio da vida de que o poder se incumbiu, um corte: o corte entre o que deve viver e o que deve morrer", sobre o que o autor especifica:

No contínuo biológico da espécie humana, o aparecimento das raças, a qualificação de certas raças, a distinção das raças, a hierarquia das raças, a qualificação de certas raças como boas e outras, ao contrário, como inferiores, tudo isso vai ser uma maneira de fragmentar esse campo biológico de que o poder se incumbiu: uma maneira de defasar, no interior da população, uns grupos em relação aos outros (FOUCAULT, 1999, p.304).

Outro aspecto do biopoder que, conforme Foucault (1999, p. 305), possibilita fazer morrer ainda que no interior da política da vida, é a justificativa ligada a uma relação do tipo guerreiro em que se compreende que "para viver, é preciso que você massacre seus inimigos". Dessa forma, ao pensarmos na entrada de igrejas evangélicas em terras indígenas, como observamos em Ex-Pajé (2018), estamos pensando em formas de controle e morte dessas populações, pois, de acordo com Foucault (1999), no interior deste corte estabelecido pelo biopoder que separa aqueles devem viver dos que devem morrer:

[...] 'quanto mais as espécies inferiores tenderem a desaparecer, quanto mais os indivíduos anormais forem eliminados, menos degenerados haverá em relação à espécie - viverei, mais forte, serei, mais vigoroso serei, mais poderei proliferar'. A morte do outro não é simplesmente a minha vida, na medida em que seria a minha segurança pessoal; a morte do outro, a morte da raça ruim, da raça 
inferior (ou do degenerado, ou do anormal), é o que vai deixar a vida em geral mais sadia; mais sadia e mais pura (FOUCAULT, 1999, p. 305).

Além da morte do corpo, do indivíduo, ou da população, pelo genocídio, no biopoder, Gonçalves (2012) destaca ainda que "se deixa morrer hábitos, costumes, crenças, línguas e tudo o que destoa daquilo que se estabelece por unidade nacional" ", "matam-se os hábitos, os costumes, as línguas e as crenças" (GONÇALVES, 2012, p. 45). Ainda que no biopoder, diferentemente do pleno poder soberano, o imperativo seja fazer viver, observamos no filme Ex-Pajé (2018) a ação do homem branco no interior do biopoder que, tanto por mecanismos disciplinares quanto regulamentadores, faz morrer aspectos da cultura indígena perante a perda da sua religiosidade como uma estratégia biopolítica.

\section{A RESISTÊNCIA AO GENÓCIDIO INDÍGENA CONTEMPORÂNEO MATERI- ALIZADO NA IMAGEM EM MOVIMENTO DE EX-PAJÉ}

"- Quando se inventam assim maldades sobre um povo, é para abençoar as maldades que se vão praticar sobre ele"

(Mia Couto)

O filme Ex-Pajé (2018) se inicia com uma citação do antropólogo francês Pierre Clastres na qual se lê: "O Etnocídio não é a destruição física dos homens, mas do seu modo de vida e pensamento. Enquanto o genocídio assassina os povos em seu corpo, o etnocídio os mata em seu espírito" (CLASTRES, 2004, p. 56). Tal fato é importante para compreendermos a marcação de uma posição de sujeito autor no início do filme. Ainda que não haja um narrador ativo atuando como personagem e contando os fatos no decorrer da história, a citação inicial deflagra a evidência desse processo biopolítico que marca o norte da narrativa: a aniquilação do povo Paiter Suruí por meio da morte dos seus costumes e, mais especificamente, de suas práticas de religiosidade com a missão de doutrinação cristã presente na aldeia. Observa-se também, que o diretor optou por não utilizar o recurso da voz, enquanto produção verbal de modalidade oral, apenas o da leitura silenciosa a cargo do espectador, sobre um fundo preto com as letras brancas preenchendo discretamente o espaço da tela.

A citação é seguida por dois trechos de filmes de arquivos (Quadro

2. Ao escrever o artigo pensamos não em uma nacionalidade indígena, mas sim em povos que unificados politicamente lutam pelo direito de existência. Nesse sentido a compreensão de unidade nacional reside justamente no pólo oposto ao indígena, ou seja, no pólo da cultura branca que, conforme Foucault (1999), desde a colonização, exerce o direito soberano de matar, praticando o genocídio colonizador. 
1), em que se registram o território Paiter Suruí e os primeiros contatos com os homens brancos ${ }^{3}$, em 1969. Tais imagens discursivizam o acontecimento factual de contato dos Paiter Suruí com o homem branco, as imagens em sua dimensão de enunciado emergem como um acontecimento discursivo ${ }^{4}$, tendo em vista que o regime de verdade sobre esses povos nunca mais será o mesmo, pois desestabiliza as estruturas que estavam ali fixadas.

A partir do momento em que o homem branco registra a existência desse povo nativo por meio de imagens, eles passam a existir para o mundo branco ocidental, conforme corrobora Sontag ao descrever que "Fotografar é apropriar-se da coisa fotografada. Significa pôr a si mesmo em determinada relação com o mundo semelhante ao conhecimento e, portanto, ao poder" (SONTAG, 2004, p.14). Nesse regime de verdade, desde as primeiras imagens que atuam como modo de objetivação do sujeito indígena Suruí, este é colocado no jogo do poder e anexado a dispositivos colonizatórios que irão produzir novas subjetividades para estes sujeitos, visto que, como observamos com Foucault (1995) o poder

[...] aplica-se à vida cotidiana imediata que categoriza o indivíduo, marca-o em sua própria individualidade, liga-o à sua própria identidade, impõe-lhe uma lei de verdade, que devemos reconhecer e que os outros têm que reconhecer nele. É uma forma de poder que faz dos indivíduos sujeito (FOUCAULT, 1995, p. 235).

Assim, esse processo de objetivação/subjetivação pode ser observado nos enunciados materializados nos frames que reproduzimos

\section{a seguir:}

3. Conforme se descreve no site Povos Indígenas no Brasil, no texto Surui Paiter (s/d) os paiter emigraram de "[...] Cuiabá para Rondônia no século XXI, fugindo da perseguição de brancos." Devido ao grande fluxo migratório para Rondônia motivado pela exploração da borracha e também da construção da estrada de ferro Madeira Mamoré. Tal fato fez com que os Paiter ficassem cada vez mais expostos aos não-indígenas, o que gerou conflitos de terra. Somente em 1969 há um contato da Funai com os nativos e a demarcação do território indígena nomeado Sete de Setembro, entretanto, muitos indígenas permaneciam fora do espaço demarcado, situação que mudou apenas com uma pandemia de sarampo que matou mais de 300 índios. A demarcação do território indígena Sete de Setembro só aconteceu de fato em 1983. A partir dos anos 80, os Paiter Surui tiveram metade das suas terras tomadas por um projeto de construção da Rodovia Cuiabá-Porto Velho, Programa Polonoroese (Programa Integrado de Desenvolvimento do Noroeste do Brasil) patrocinado pelo Banco Mundial, além de invasões de fazendeiros. Disponível em: https://pib.socioambiental.org/pt/Povo:Surui_Paiter\#Hist.C3.B3rico_do_contato. Acesso em 17 de agosto de 2021.

4. Foucault (2008b, p. 28) demarca para o método arqueológico de análise do discurso a necessidade de "estar pronto a acolher cada momento do discurso em sua irrupção de acontecimentos, nessa pontualidade em que aparece e nessa dispersão temporal que lhe permite ser repetido, sabido, esquecido, transformado, apagado [...]" e, a partir disso, descreve que "um enunciado é sempre um acontecimento que nem a língua nem o sentido podem esgotar inteiramente. [...] está ligado, de um lado, a um gesto de escrita ou à articulação de uma palavra, mas por outro lado, abre para si mesmo uma existência remanescente no campo de uma memória, ou na materialidade [...] é único como todo acontecimento, mas está aberto à repetição, à transformação, à reativação; [...] está ligado não apenas a situações que o provocam, e a consequências por ele ocasionadas, mas, ao mesmo tempo, e segundo uma modalidade inteiramente diferente, a enunciados que o precedem e o seguem" (FOUCAULT, 2008b, p. 3132 ). 
Quadro1 - O território Pater Suruí e o primeiro contato com o homem branco

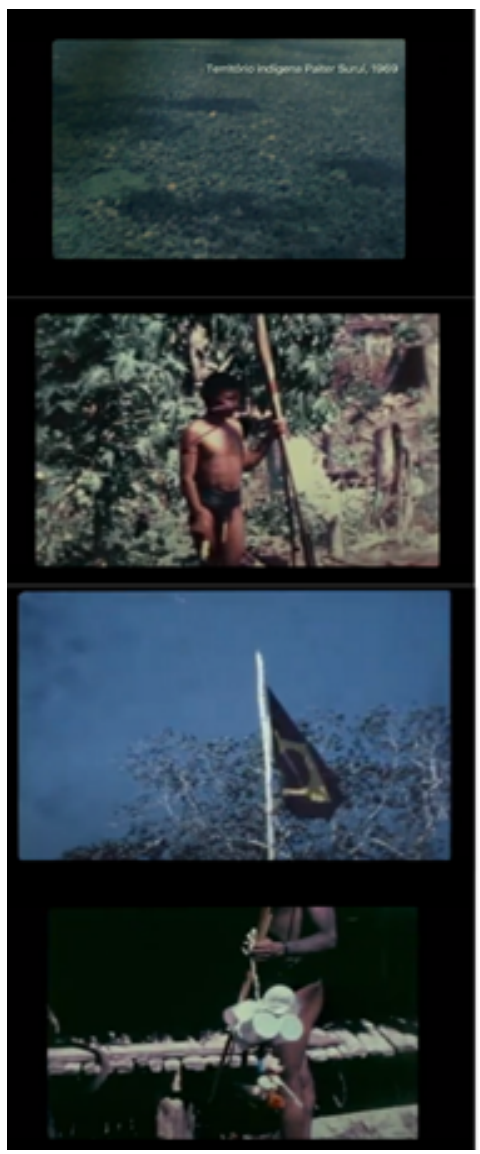

frame 1

frame 2

frame 3

frame 4

Fonte: Ex-Pajé (2018, 00h. 01m. 18s - 00h. 03m. 10s.).

No que concerne à construção da narrativa do filme, a retomada das imagens que recuperamos no Quadro 1 pode ser melhor compreendida se abordada por meio do conceito de comentário, elaborado por Foucault (2014b) enquanto um procedimento interno de controle do discurso. Pelo comentário compreendemos essa narrativa que, deslocada da sua emergência "primeira", entendida mais pertinentemente como anterior, diz novamente por meio de atos enunciativos novos no interior dos quais ela é, na verdade, dita. No comentário que observamos, há o estabelecimento de um desnível entre o enunciado primeiro e o enunciado segundo que permite "dizer enfim o que estava articulado 
silenciosamente no texto primeiro" no paradoxo de "dizer pela primeira vez aquilo que, entretanto, já havia sido dito e repetir incansavelmente aquilo que, no entanto, não havia jamais sido dito" (FOUCAULT, 2014b, p. 25).

Em Ex-Pajé (2018), a retomada da sequência fílmica obtida em 1969 funciona como comentário na medida em que - respondendo às condições de possibilidade a que a produção enunciativa em questão se ligava no momento de sua produção em 1969 e obedecendo ao paradoxo observado por Foucault (1999) - diz pela primeira vez aquilo que já havia sido dito e repete incansavelmente o que jamais havia sido dito: a invasão branca a uma cultura indígena. Se, em 1969, o vídeo podia ser lido como registro do "progresso" pelo qual passava o Brasil, como registro de apropriação por parte do Estado de um território nacional brasileiro (cuja evidência observamos na bandeira colocada em território indígena recuperada no frame 3), em 2018, a sua reativação das imagens em uma nova sequência fílmica, no interior de uma outra vontade de verdade, faz com que ele seja lido como denúncia do genocídio cultural do povo Paiter Suruí.

Ainda sobre esse movimento de contato dos Suruí com o povo branco estar discursivizado nas imagens de arquivo recuperadas pelo diretor do filme, retomamos a escrita de Sontag ao evidenciar que, no interior de um regime de verdade, "Uma foto equivale a uma prova incontestável de que determinada coisa aconteceu. A foto pode distorcer, mas sempre existe o pressuposto de que aquilo existe, ou existiu, e era semelhante ao que está na imagem" (SONTAG, 2013, p. 17), uma vez que enquanto enunciado a foto, a imagem se insere num regime de verdade ${ }^{5}$.

A partir disso, o filme se segue, levando o telespectador para o contexto contemporâneo da vida na aldeia Paiter Suruí, e nos apresenta a uma outra realidade que não a dos homens despidos e marcadamente com os adereços de sua cultura como no registro feito em 1969, visto que, como descrito anteriormente, após a instalação de uma missão evangélica, estabeleceu-se uma nova prática de conduta que modifica o regime de olhar de verdade daquela comunidade sobre a sua espiritualidade (Quadro 2): o filme registra a existência de uma compreensão entre o povo nativo segundo a qual há uma demonização da religiosidade nativa, cuja liderança tem a figura do pajé, e a assimilação

5. Podemos compreender regime de verdade a partir de Foucault (2008c, p. 27) quando, ao retomar a loucura, a doença, a delinquência e a sexualidade a título de exemplificação, este demonstra como "o par 'série de práticas/ regime de verdade' forma um dispositivo de saber-poder que marca efetivamente no real o que não existe e submete-o legitimamente à demarcação do verdadeiro e do falso", sendo o regime de verdade, portanto, um regime que subordina o que está inscrito no real à demarcação de verdadeiro e falso. 
de uma religião cristã. Tal acontecimento fomenta a rejeição de Perpera, inclusive entre os habitantes da aldeia, enquanto pajé, fazendo com que ele seja impelido a se afastar das práticas comuns ao posto de pajé, como o diálogo ativo com o Espírito do Rio e a cura de doenças.

Nesse contexto, pelo frame 1 do Quadro 2, observa-se Perpera indo para a igreja numa cena que procede de um relato de Perpera à beira do rio, e no qual ele relembra um período anterior à inserção do cristianismo entre eles e como, enquanto pajé, mantinha contato com o Espírito do Rio e dele recebia os peixes para o alimento de seu povo. Nessa sequência fílmica, Perpera descreve também como a sua atuação de pajé, desde a introdução da crença cristã e da figura do pastor no território Suruí, passou a ser objetivada como demoníaca, como os membros da tribo foram se tornando cristãos e por isso deixando de falar com Perpera. O pajé explica como, em decorrência disso, ele passou a frequentar a igreja cristã com o objetivo de que os membros de seu povo voltassem a falar com ele. No frame em questão, Perpera segue pelo meio da mata, vestido formalmente, em uma roupa na qual não aparenta estar confortável. Esta roupa é composta por um excesso de tecidos, que não parecem vesti-lo adequadamente. A roupa de estilo social destoa da mata e não parece se encaixar com aquele ambiente, ela é composta por bastante tecido e caracteriza um estilo de vestimenta prototipicamente utilizada em ambientes urbanos, em ocasiões formais da vida urbana e de grandes centros, mais comum em climas de regiões frias como o hemisfério norte (países europeus, Estados do Unidos da América).

No frame 1 do Quadro 2, Perpera é centralizado à imagem da mata que o cerca. Nas roupas que ele veste e que marcam a separação física e visual entre seu corpo e a floresta ao seu redor, observamos muitas sobras de tecido, principalmente nas mangas da camisa, o que nos indica algo deslocado de seu lugar.

Ao confrontarmos as imagens presentes nos frames 2 e 4 do Quadro 1 com as imagens dispostas nos frames do Quadro 2 podemos observar como o poder disciplinar ligado ao biopoder age na manipulação do corpo tornando-o dócil e útil. O corpo dos homens e mulheres do povo Suruí registrado nas imagens feitas ao primeiro contato com os brancos no Quadro 1 ressurge no registro contemporâneo do Quadro 2, tendo sido disciplinarizado e, portanto, vestido com camisa, gravata e calça social. 
Quadro 2 - Espiritualidade (práticas biopolíticas de subjetivação)

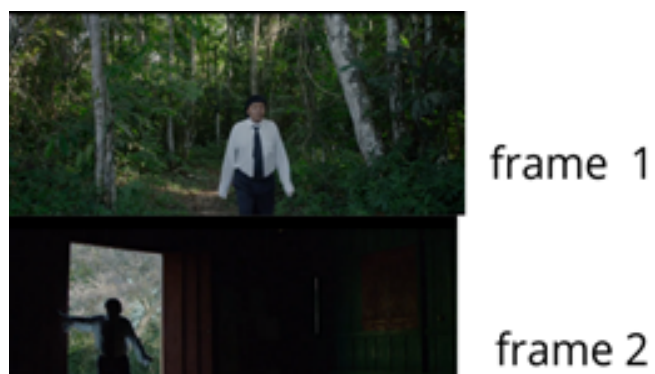

frame 3

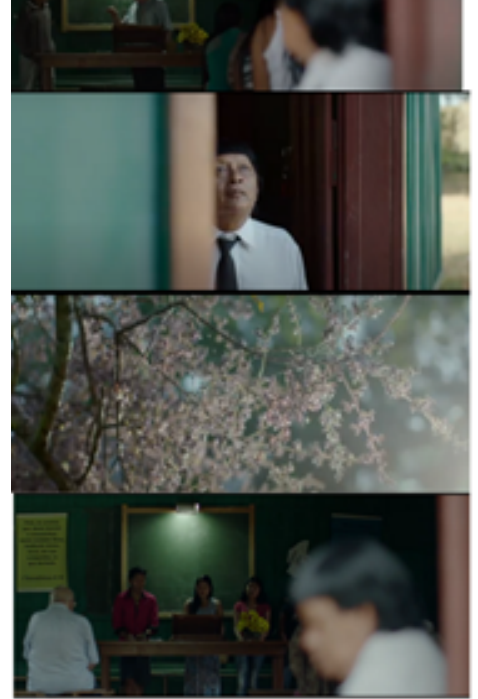

frame 4

frame 5

frame 6

Fonte: Ex-Pajé (2018, 00h15m22s - 00h20m02s).

Conforme registra a materialidade discursiva do documentário, Perpera tem sua função de Pajé suprimida pelo poder pastoral e assume para si o papel de uma espécie de porteiro da igreja evangélica, na qual ele atua abrindo as portas e janelas, limpando o espaço e sendo o responsável por deixar tudo em ordem para o começo do sermão ${ }^{6}$ (frame 2). Entretanto, observa-se, no filme, que o personagem senta-se à porta da igreja (frame 3), distante do púlpito, e mesmo com uma oferta tentadora do pastor que ao pregar promete "a vida eterna", Pérpera observa a natureza, olhando atentamente para uma árvore florida (frame 6. O sermão é feito em português e traduzido para o Tupi Mondé (língua da aldeia) por um indígena local. 
4) que é sobrevoada por vários insetos e cujo som do bater das asas fica gradativamente mais intenso (frame 5), abafando por completo a voz daquele que enuncia do interior da igreja. O olhar de Perpera indica a sua conexão com o encantado ${ }^{7}$, com o Espírito da Floresta que fala com ele. Ao final do culto, os indígenas que saem da igreja cumprimentam Perpera em sinal de respeito, o distanciamento entre ele e o pastor (frame 6) evidencia a separação entre esses dois sujeitos que são líderes respectivos de cada crença, mas cujo êxito, sob o registro da materialidade discursiva observada, apenas o pastor evangélico atingiu naquele momento.

O poder pastoral, que Foucault (2008a, p. 168) identifica no antigo Oriente mediterrâneo, é aquele exercido por um pastor, deus ou chefe que atua sobre os homens, os quais compõem seu "rebanho", e que está ligado à relação entre Deus e os homens, sendo, desse modo, "um poder do tipo religioso que tem seu princípio, seu fundamento, sua perfeição no poder que Deus exerce sobre seu povo". Este poder do pastor, nos explica o filósofo, incide não sobre o controle do território, mas é um poder que se exerce sobre um rebanho e que atua conduzindo o rebanho em questão, fazendo-o ir de um ponto a outro. À vista disso, os relatos de Perpera no documentário, que antecedem e sucedem a cena recuperada pelo Quadro 2, nos permitem localizar a atuação do poder pastoral sobre os Paiter Suruí, conduzindo-os de uma prática de espiritualidade que envolvia a atuação do Pajé como líder à crença cristã, que ao objetivar os indígenas como "filhos de Deus" subjetiva-os em rebanho e objetiva as práticas de Perpera como demoníacas.

Complementarmente, o poder regulamentar - que, conforme Foucault (1999), age sobre a vida da população, sobre os efeitos de massa da população em geral e dos corpos em conjunto - é observado a partir da regulamentação da adoção das práticas religiosas cristãs em detrimento da imperativa ordem de abandono das práticas tradicionais indígenas que tem como escopo todo o povo Paiter Suruí e modifica inclusive suas práticas ligadas à cura de doenças e medicalização dos corpos.

Entretanto, a resistência de Perpera frente ao genocídio cultural que o poder pastoral impõe especificamente se marca na medida em que ele vai à igreja cristã para manter sua ligação com seu povo. Nesse ambiente, Perpera atua como porteiro, pelas suas mãos o espaço do culto ao deus

7. Pensamos aqui nos encantados como divindades espirituais da natureza ligadas aos ritos e magias dos povos indígenas, e também com entidades ancestrais ligadas ao místico. Fonte: http://basilio.fundaj.gov.br/ pesquisaescolar/index.php?option=com_content\&view=article\&id=308 
dos homens brancos se abre e se fecha. O culto não lhe pertence, tanto que à porta da igreja, enquanto o pastor enuncia ao fundo, como vimos pela sequência dos frames 3 e 4 no Quadro 2, ele mantém seu olhar e sua atenção voltada para a floresta e ela fala com ele. Encerrado o ritual branco, Perpera varre o chão da igreja e fecha o espaço que ele mesmo abrira anteriormente, evidenciando ser sua a chave que controla o lugar do sagrado para seu povo.

Ainda que sua atuação neste espaço não seja marcadamente como a de líder, Perpera faz pelo seu povo aquilo que seu ofício de pajé exige que ele faça, ou seja, permanecer junto dele ainda que no interior de uma crença com a qual ele não compactua. Por essa escolha, Perpera relata ao longo documentário que não pode mais dormir de luzes apagadas, pois, quando não há luz em seu quarto durante a noite, ele apanha dos Espíritos que estão bravos com ele por ir à igreja cristã.

Nesse sentido, as imagens que recuperamos em nossas análises nos Quadros 1 e 2 constituem-se por símbolos que demonstram o biopoder, a biopolítica atuando na subjetivação do sujeito indígena. Ao ter o primeiro contato com o homem branco (discursivizado no Quadro 1), abrem-se caminhos para uma disciplina de controle dos corpos desse povo como demonstrado no Quadro 2 em que o dispositivo colonial se reatualiza na contemporaneidade, promovendo uma negação e uma demonização dos aspectos culturais e religiosos que podem resultar na morte do sujeito indígena e consequente subjetivação de um outro sujeito.

No entanto, Perpera Suruí, ao contrário do quer que se pressuponha pelo título do documentário, logo Ex-Pajé (2018), resiste a dessubjetivação que lhe tiraria do lugar de pajé e mantém suas práticas transversais de atuação desse mesmo lugar ao controlar o espaço em que seu povo agora ocupa numa nova prática de espiritualidade e sob a subjetivação de rebanho, ou seja, a igreja cristã no interior da floresta.

\section{CONSIDERAÇÕES FINAIS}

Considerando que o biopoder consiste em formas de governamentabilidade da sociedade e que isso se dá por meio de estratégias de disciplina do corpo e de regulamentação da população, buscamos demonstrar em nossas análises como o dispositivo colonial se refaz na contemporaneidade para controle da população dos povos indígenas. Para realizar o estudo aqui apresentado tomamos como ponto de partida sobretudo os conceitos de biopoder para Michel Foucault e 
de dispositivo para Giorgio Agamben e analisamos o filme documentário brasileiro Ex-Pajé (2018) dirigido por Luiz Bolognesi. Por se tratar de uma materialidade longa em relação ao espaço reservado para a escrita do artigo, fizemos um recorte de dois momentos do filme:

1) O primeiro contato do grupo Paiter Suruí com os nãoindígenas;

2) A primeira cena que o Perpera vai até a igreja evangélica da sua aldeia para a pregação do pastor.

Por nossas análises, foi possível observar que, a partir das imagens constituídas por símbolos e aqui retomadas como enunciados discursivos, o primeiro contato do não-indígena com o povo Paiter Suruí coloca-os em um acontecimento factual e discursivo de "descobrimentos" desses povos para iniciar um processo de inseri-los no mundo hegemonicamente branco, colonizado pela Europa Ocidental. Tal acontecimento, inegavelmente, promove o genocídio desses povos.

O genocídio se dá não apenas na forma de aniquilação da vida, mas na aniquilação da prática da cultura, da religiosidade e dos costumes desses povos. A inserção de igrejas evangélicas acontece contemporaneamente em uma nova forma de catequização desses povos e se evidencia enquanto biopolítica atuando na subjetivação de um outro sujeito indígena. Ao mesmo tempo, aquele que querem crer teria se tornado um ex-pajé atua em práticas de resistência se reaproximando de seu povo ao adentrar o novo espaço de culto, agora cristão, sem, contudo, se desligar completamente das práticas que o constituem ainda pajé, atuando, como observamos no documentário, informalmente e em conversas cotidianas, nas quais cuida de seu povo e simultaneamente ensina um menino indígena pelo qual chamam pajézinho na tribo. Desse modo, Perpera Suruí permanece Pajé, apesar do genocídio cultural, apesar do cristianismo, apesar da demonização de sua prática e apesar do pastor.

O filme e os frames apresentados nos quadros 1 e 2, embora sem o que se poderiam considerar grandes ações, discursiviza alguns aspectos da tensão existente nos mais de 500 anos de exploração e invasão das terras indígenas, por isso, tais frames são extremamente violentos, visto que o que permanece em jogo é o poder sobre vida e morte de um povo.

\section{REFERÊNCIAS}

AGAMBEN, Giorgio. O que é contemporâneo? E outros ensaios. trad. Vinícius Nicastro Honesco. Chapecó: Argos, 2009. 
BURKE, Peter. Testemunha ocular: história e imagem. trad. Vera Maria Xavier dos Santos. Revisão técnica Daniel Aarão Reis Filho. Bauru: EDUSC, 2004.

CLASTRES, Pierre. Arqueologia da violência: pesquisas de antropologia política. Cidade: Cosac \& Naif, 2004. CONSIDERAÇÕES FINAIS

COUTO, Mia, 1955. O outro pé da sereia: (romance) - Mia Couto. São Paulo: Companhia das Letras, 2006.

ETNOAMBIENTAL, Kanindé Associação de Defesa - MINDLIN, Betty - URU-EU-WAUWAU, Jupaú - Associação do povo Índigena. SUITER PAITER, 2003. Disponível em: https://pib.socioambiental.org/pt/Povo:Surui_Paiter\#Hist.C3.B3rico_do_contato Acesso em 09 de novembro de 2020 às 23:35.

FOUCAULT, Michel. Do governo dos vivos: curso do Collège de France (1979-1980). trad. Eduardo Brandão. São Paulo: WMF Martins Fontes, 2014a.

FOUCAULT, Michel. A ordem do discurso: aula inaugural no Collège de France, pronunciada em 2 de dezembro de 1970. 24. ed. trad. Laura Fraga de Almeida Sampaio. São Paulo: Edições Loyola, 2014b.

FOUCAULT, Michel. Segurança, território, população: curso do Collège de France (1977-1978). trad. Eduardo Brandão. São Paulo: Martins Fontes, 2008a.

FOUCAULT, Michel. A arqueologia do saber. 7. ed. trad. Luiz Felipe Baeta Neves. Rio de Janeiro: Forense Universitária, 2008b.

FOUCAULT, Michel. Nascimento da biopolítica: curso dado no Collège de France (19781979). trad. Eduardo Brandão. São Paulo: Martins Fontes, 2008c.

FOUCAULT, Michel. Verdade e poder. In: FOUCAULT, Michel. Microfísica do poder. Organização e tradução de Roberto Machado. 24.ed. Rio de Janeiro: Edições Graal, 2007.

FOUCAULT, Michel. Em defesa da sociedade: curso no Collège de France (1975-1976). trad. Maria Ermantina Galvão. São Paulo: Martins Fontes, 1999.

FOUCAULT, Michel. O sujeito e o poder. In: DREYFUS, Hubert L. e RABINOW, Paul. Michel Foucault: uma trajetória filosófica. trad. Vera Porto Carrero. Rio de Janeiro: Forense Universitária, 1995. p. 230-249.

GONÇALVES, Raquel Fregadolli Cerqueira Reis. Cidadania, Inclusão e Biopolítica: A Identidade Linguística em Contradição no Processo Seletivo "Vestibular dos Povos Indígenas no Paraná", 2012. Dissertação (mestrado) - Programa de Pós-Graduação em Letras da Universidade Estadual de Maringá, Maringá.

MACHADO, Regina Coeli Vieira. Lendas Indígenas. Pesquisa Escolar Online, Fundação Joaquim Nabuco, Recife. Disponível em: <http://basilio.fundaj.gov.br/pesquisaescolar>. 
Visualizado em: 10 de novembro de 2020 às 17:12.

MACHADO, Roberto. Introdução: por uma genealogia do poder. In: MACHADO, Roberto. Microfísica do poder. Organização e tradução de Roberto Machado. 24.ed. Rio de Janeiro: Edições Graal, 2007.

MANGUEL, Alberto. A imagem como enigma. In: MANGUEL, Alberto. Lendo imagens: uma história de amor e ódio. São Paulo: Companhia das Letras, 2001.

MARTINS, Luiz Alberto Moreira; JUNIOR, Carlos Augusto Peixoto. Genealogia do Biopoder. Psicologia \& Sociedade; 21 (2): 157-165, 2009.

OTTO, Claricia; SOUZA, Diogo Matheus de. Ex-Pajé: Cultura do povo indígena Paiter Suruí e a memória como resistência. Travessias, Cascavel, v14, n2, p. 365 - 369, maioago. 2020.

SONTAG, Susan. Na caverna de Platão. In: SONTAG, Susan. Sobre Fotografia. Tradução de Rubens Figueiredo. São Paulo: Companhia das Letras 2009.

OLIVEIRA, Valéria Cristina de; TASSO, Ismara. Documentário e Narratividade: movimentos tecnológicos e enunciativos. In: TASSO, Ismara; CAMPOS, Jefferson (orgs). Imagem e(m) Discurso - A formação das Modalidades Enunciativas. Coleção: Linguagem \& Sociedade. vol 8. Campinas: Pontes Editores, 2015. p.119-137.

FILMOGRAFIA

EX-PAJÉ. Direção: Luiz Bolognesi. 2018, Brasil, $81 \mathrm{~min}$. COR, Produzido por: Laís Bodanzky e Luiz Bolognesi. Documentário. Buriti Filmes e Gullane

IMAGENS AÉREAS DE HABITAÇÃO PAITER SURUí ANTES DO CONTATO. Direção: Jorge Bodanzky. 1969.

wew

VÍDEO DO CONTATO DOS PAITER SURUÍ COM O HOMEM BRANCO. Câmera: Jesco Von Puttkamer, Acervo PUC Goiás-IGPA

SUBMETIDO EM: 31/08/2021

ACEITE EM: 22/10/2021 